\title{
Çocuklarda Kulak Burun Boğaz Muayene Sonuçları ve Etkileyen Faktörler: Okul Tabanlı-Kesitsel Çalışma
}

\author{
Ear, Nose and Throat Examination and Affecting Factors in Children: a School Based-Cross Sectional \\ Study
}

\author{
Murat Tekin ${ }^{1}$, Medine Kara², Ayşegül Uludağ ${ }^{1}$, Yusuf Haydar Ertekin ${ }^{1}$, Satı Zeynep Tekin ${ }^{3}$, Erkan Melih Şahin ${ }^{1}$, \\ Fevzi Sefa Dereköy ${ }^{2}$
}

${ }^{1}$ Aile Hekimliği Ana Bilim Dalı, Tıp Fakültesi, Çanakkale Onsekiz Mart Üniversitesi, Çanakkale, Türkiye

${ }^{2}$ Kulak Burun Boğaz Hastalıkları Ana Bilim Dalı, Tıp Fakültesi, Çanakkale Onsekiz Mart Üniversitesi, Çanakkale, Türkiye

${ }^{3}$ Tıbbi Mikrobiyoloji Ana Bilim Dalı, Tıp Fakültesi, Çanakkale Onsekiz Mart Üniversitesi, Çanakkale, Türkiye

\section{ÖZET}

Giriş: Çalışmada okul çağı popülasyonunda kulak burun ve boğaz muayenesi yaparak sık görülen patolojileri ve bu durumlarla ilişkili faktörleri saptamak amaçlanmaktadır.

Yöntem: Kesitsel desendeki çalışma Eylül-Aralık.2013 tarihleri arasında Çanakkale il merkezindeki ilk ve ortaokullarda yapıldı. Öğrencilerin ve ailelerinin hastalık öykülerini ve alışkanlıklarını sorgulayan anket uygulandı. Kulak, burun ve boğaz muayeneleri yapılarak, öğrencilerin muayene formlarına not edildi.

Bulgular: Çalışmaya toplam 1938 öğrenci alındı. Öğrencilerin 1369 (\%70,6)'u ilkokul, 569 (\%29,4)'ü ortaokulda eğitim görmekteydi. Öğrencilerin yaş ortalaması $8,6 \pm 2,3$ idi. Çalışmada sırasıyla tonsiller hipertrofi $\% 25,2$, kepçe kulak $\% 14,8$, otitis media $\% 3,3$, anterior nazal deviasyon \%10,4 sıklıkta gözlendi. Kepçe kulak erkek öğrencilerde daha fazlaydı $(p<0,001)$. Öğrencilerin cinsiyet ve okul seviyeleri ile kulak, burun ve boğaz patolojisinden en az birinin bulunma durumu arasında anlamlı farklılık yoktu ( $p>0,05)$.

Sonuç: Okul çocuklarında sırasıyla tonsiller hipertrofi, anterior nazal deviasyon ve otitis media en sık saptanmıștı. Öğrencilerin ve ailelerinin tıbbi öykü özellikleri ile ailelerin tıbbi öykü ve alışkanlıkları, kulak, burun ve boğaz patolojisinin varlığı için risk faktörü değildi.

Anahtar kelimeler: Okul Çağı Popülasyonu, Tonsil, Nazal Septum, Otitis Media, Sıklık

\begin{abstract}
Introduction: In this study, we aimed to determine the most common pathologies by examining the ear, nose and throat (ENT) of school-aged population and the relation with the associated factors.

Methods: A cross-sectional study was conducted between September-December 2013 at the primary and secondary schools in the city center of Çanakkale. A questionnaire was applied with the students' and parents' disease history and their habits. Ear, nose and throat examination was performed and noted to the examination form.

Results: A total of 1938 students were enrolled in the study. 1369 students (70.6\%) were in primary schools, 569 (29.4\%) were in secondary schools. Mean age of the students was $8.6 \pm 2.3$ years. The prevalence of tonsillar hypertrophy was $25.2 \%$, prominent ear $14.8 \%$, otitis media $3.3 \%$, anterior nasal deviation $10.4 \%$ respectively. Prominent ear were found more frequent in male children than female children $(\mathrm{p}<0,001)$. There were no significant differences between children according to gender and the level of classes with having at least one ear-nose-throat pathology $(\mathrm{p}>0.05)$.

Conclusion: Tonsillar hypertrophy, anterior nasal deviation, and otitis media were the most common pathologies in the school aged children respectively. The students' and the parents' medical histories and the parents' habits were not risk factors for having at least one ear-nose-throat pathology.
\end{abstract}

Keywords: School Age Population, Tonsil, Nasal Septum, Otitis Media, Frequence

Başvuru / Submission: Nisan / April 01, 2016

Kabul / Acceptance: Nisan / April 22, 2016

Yazışma / Correspondence: Dr. Murat Tekin, Çanakkale Onsekiz Mart Üniversitesi, Tıp Fakültesi Hastanesi Yeni Binası, Aile Hekimliği AD. Kat 5, Öğretim Üyesi Odaları Merkez/Çanakkale.

Tel: +90 (286) 2635950 - 2539

E-mail: drmurattekin@yahoo.com

Atıf / Cite: Tekin M, Kara M, Uludağ A, Ertekin YH, Tekin Z, Şahin EM, Dereköy FS. Çocuklarda Kulak Burun Boğaz muayene sonuçları ve etkileyen faktörler: Okul tabanlı-kesitsel çalışma. 2016;1(1):19-23 


\section{GíRIŞ}

Kulak, burun ve boğaz (KBB) patolojileri tüm yaş gruplarında sık görünmekte ve ateş, halsizlik, kırgınlık gibi akut semptomlara, işitme kaybı gibi kronik semptomlara neden olmaktadır. Bütün yaş gruplarında sağlık hizmetlerine en çok başvuru sebepleri arasında KBB'ye bağlı rahatsızlıklar ilk siralarda yer almaktadir.

Mikroorganizmaların neden olduğu hastalıklara bağlı gelişen ya da kendisi enfeksiyona kaynak oluşturan tonsil hipertrofisi, nazal deviasyon, otitis media gibi patolojiler çocukları oldukça sık etkilemektedir. $\mathrm{Bu}$ hastalıklar, uzun dönemde büyüme ve gelişme geriliği ve hatta entellektüel düzeyde düşmeye neden olması nedeniyle ayrıca önem kazanmaktadır.

Tonsil hipertrofisi sık geçirilen enfeksiyona bağlı olarak gelişir ve muayene bulgularına göre sınıflandırılır (1). Nazal deviasyon anterior ve posterior olmak üzere ikiye ayrılırken, anterior nazal deviasyon kolaylıkla inspeksiyonla ayırt edilebilir ve çoğunlukla travmaya bağlıdır. Çocukluk çağında s1k görülen otitis media; akut ve kronik süpüratif otitis media, seröz otitis media ve sekelleri olarak alt gruplara ayrılmakta ve 5 yaşa kadar çok sık görülmektedir (2). Çocuklarda sık görülen ve ek morbiditeye neden olan KBB patolojilerinin belirlenmesi toplum sağlığı açısından önem taşır. Özellikle bu patolojilere bağlı gelişen kronik komplikasyonların çoğu çocuğun okul çağında entelektüel kapasitenin de kullanılmaya başlanmasıyla ya öğretmenler ya da velileri tarafindan fark edilir. Çalışmamızda da okul çağı çocuklarında kulak burun ve boğaz muayenesi yaparak sik görülen patolojileri ve bu durumlarla ilişkili risk faktörlerini saptamak amaçlanmaktadır.

\section{YÖNTEM}

Tanımlayıcı desendeki çalışma 16 Eylül - 30 Aralık 2013 tarihleri arasında Çanakkale il merkezinde ilk ve orta düzeydeki okullarda yapıldı. Çanakkale il merkezinde bulunan ilk ve ortaokullar çalışmanın evrenini oluşturdu. Çanakkale ilindeki 5 mahalleden küme örneklem yapılarak her mahalleden birer ilk ve ortaokulun çalışmaya alınması planlandı. Sosyo-ekonomik düzey de dikkate alınarak düşük, orta ve yüksek gelir düzeyine sahip ailelerin devam ettiği okullar seçildi. Böylece her mahalleden birer okul toplamda 5 okuldaki tüm öğrenciler çalışmaya davet edildi. Katılmayı kabul edenler çalışmaya alındı.

Çanakkale Onsekiz Mart Üniversitesi Tıp Fakültesi Aile Hekimliği, Çocuk Sağlığı ve Hastalıkları, Kulak Burun Boğaz, Dermatoloji ve Halk Sağlığı Anabilim Dalı Öğretim üyelerinden oluşan ekip sağlık taramasını gerçekleştirdi. Bu araştırma makalesinde elde edilen verilerin bir kısmı paylaşılmıştır. Çanakkale Onsekiz Mart Üniversitesi Klinik Araştırmalar Etik Kurulu ve Çanakkale İl Milli Eğitim Müdürlüğünden yazılı alınan izinlerle çalışmaya başlandı. Belirlenen ilk ve ortaokullara ulaşılarak, çalışmanın metodu anlatıldı, okul idaresinden çalışma izni istendi. İzin alınan okullarda veli toplantılarına katılarak velilerden sözlü ve yazılı izin istendi. İzin alınan öğrenciler çalışmaya alındı.

\section{Uygulama}

Çalışmaya katılımı kabul eden velilere öğrencinin natal ve prenatal öyküsü ile hastalık özgeçmişini, ebeveynlerin hastalık öyküsü, sigara kullanımları ve işitme azlığını sorgulayan anket uygulandı. Çalışmaya katılımı kabul eden öğrenciler okul idaresinin göstermiş olduğu muayene yerlerine erkek ve k1z olarak 5'erli gruplar halinde alındı.

Kulak değerlendirilmesinde kepçe kulak, dış kulak yolu atrezisi, otitis media bulguları arandı. Öğrencilerin dış kulak değerlendirilmesinde kâğıt cetvel kullanıldı. Dış kulak helik kıvrımı kulağın en çıkıntılı olduğu yerde temporomastoid alandan 16-21 mm uzaktadır (3). $21 \mathrm{~mm}$. den fazla olan ölçümler kepçe kulak olarak tanımlandı ve not edildi. Kulakları otoskopi yardımıyla sırasıyla dış kulak yolu, kulak zarı vizualize edildi ve muayene bulguları kaydedildi. Kulak zarında efüzyon görüntüsü, opasite, bombeleşme, çökme, kızarıklık olması otitis media olarak tanımlandı (4). Çalışmada bu muayene bulgularının varlığında otitis media vardır şeklinde muayene kâğıtlarına not edildi. Kulak kiri (buşon) 5 kategoride değerlendirildi. Grade 0- Kulak kiri yok. Grade 1- Kulak yolunun \%25'inden azını kaplayan kulak kiri. Grade 2- Kulak yolunun \%25-50'sini kaplayan kulak kiri. Grade 3- Kulak yolunun \%50-75'ini kaplayan kulak kiri ve Grade 4- Kulak yolunun \%75'inden fazlasını kaplayan kulak kiri.

Ağız içi patolojilerin saptanmasında dil basacağı ve 1 şık kaynağı yardımıyla sırasıyla ağız içi, bukkal mukoza, tonsiller ve farenks gözlendi. Tonsiller Brodsky L. skalasına göre evre 1-4 arasında sinıflandırılarak kaydedildi. Bu sinıflamaya göre Evre 1 hipertrofide tonsil, tonsiller çukur dişında ve havayolunu $\% 25$ 'den az, Evre 2 hipertrofide \%25-\%50, Evre 3 hipertrofide $\% 50-\% 75$ ve Evre 4 hipertrofide $\% 75$ 'in üstünde oranında daraltmaktadır (1).

Burun muayenesi için öncelikle inspeksiyonla burun diş yüzeyi, septum değerlendirildi. Sonrasında otostopa takılan spekulum yardımıla her iki burunda septum deviasyonu, konkaların büyüklükleri açısından değerlendirme yapıldı. Bulgular öğrenciye ait muayene kâğıtlarına not edildi.

\section{İstatistik Analiz}

Çalışmanın verileri SPSS 19.0 programı (SPSS Inc. Chicago, USA) kullanılarak değerlendirildi. Verilerin ortalama, ortanca, standart sapma ve frekans gibi tanımlayıcı istatistikleri yapıldı. Değişkenlerin normal dağılma durumu Kolmogorov Smirnov testi ile değerlendirildi. Kolmogorov Smirnov testine göre cinsiyet ve yaş arasında anlamlı farklılık olmadığından parametrik test olarak independent $t$ testi yapıldı. Parametrik olmayan testlerden patolojilerin varlığı ile bireylerin sayısının değerlendirilmesinde ki-kare kullanıldı. $\quad \mathrm{p}<0,05$ istatistiksel olarak anlamlı kabul edildi.

\section{BULGULAR}

Çalışmada 5-14 yaş arasında toplam 1957 öğrenciye ulaşıldı ancak 1938 öğrenci çalışmaya alındı. Diğer 19 öğrenci muayeneye uyum sağlayamadıklarından çalışmaya alınmadı. Muayeneler başladıktan sonra öğrencilerden biri tonsil muayenesi sonrası diğer muayeneleri olmak istemedi. 
Tablo 1. Öğrencilerin özgeçmiş ve soygeçmiş özelliklerinin dağılımı, $n$ (\%)

\begin{tabular}{|c|c|c|c|c|c|c|}
\hline & \multicolumn{2}{|c|}{ İlkokul } & \multicolumn{2}{|c|}{ Ortaokul } & \multirow{2}{*}{$\mathbf{p}^{*}$} \\
\hline & & Muayene & Tespit & Muayene & Tespit & \\
\hline \multirow{3}{*}{ Alerji öyküsü } & Toplam & 1178 & $203(13,9)$ & 280 & $60(4,1)$ & 0,101 \\
\hline & $\mathrm{K}_{1 \mathrm{Z}}$ & 613 & 91 & 134 & 31 & \\
\hline & Erkek & 565 & 112 & 146 & 29 & \\
\hline \multirow{3}{*}{ İşitme Kaybı } & Toplam & 1186 & $15(1,1)$ & 228 & $10(0,07)$ & 0,001 \\
\hline & $\mathrm{K} 1 \mathrm{z}$ & 615 & 8 & 109 & 8 & \\
\hline & Erkek & 571 & 7 & 119 & 2 & \\
\hline \multirow{3}{*}{$\begin{array}{l}\text { Annede sigara } \\
\text { içme öyküsü }\end{array}$} & Toplam & 1175 & $343(24,5)$ & & $60(4,3)$ & 0,422 \\
\hline & $\mathrm{K}_{1 Z}$ & 611 & 188 & 111 & 31 & \\
\hline & Erkek & 564 & 155 & 115 & 29 & \\
\hline \multirow{3}{*}{$\begin{array}{l}\text { Annede işitme } \\
\text { kaybı öyküsü }\end{array}$} & Toplam & 1394 & $26(1,9)$ & & $4(0,3)$ & 0,710 \\
\hline & $\mathrm{K}_{1 \mathrm{Z}}$ & 609 & 14 & 109 & 2 & \\
\hline & Erkek & 565 & 12 & 111 & 2 & \\
\hline \multirow{3}{*}{$\begin{array}{l}\text { Babada sigara } \\
\text { içme öyküsü }\end{array}$} & Toplam & 1391 & $637(45,8)$ & & $109(7,8)$ & 0,103 \\
\hline & $\mathrm{K} 1 \mathrm{z}$ & 607 & 345 & 111 & 49 & \\
\hline & Erkek & 560 & 292 & 113 & 60 & \\
\hline \multirow{3}{*}{$\begin{array}{l}\text { Babada işitme } \\
\text { kaybı öyküsü }\end{array}$} & Toplam & 1373 & $36(2,6)$ & & $8(0,6)$ & 0,629 \\
\hline & $\mathrm{K} 1 \mathrm{z}$ & 602 & 20 & 106 & 3 & \\
\hline & Erkek & 557 & 16 & 108 & 5 & \\
\hline
\end{tabular}

*ki-kare testi, n:Muayenesi gerçekleştirilen öğrencilerin ailesi tarafından anket formunda ilgili soruya verdikleri yanıt sayısı

Kulak muayenesinde buşon ile tam kaplı olan $138(\% 7,1)$ kişini kulak zarı görülemediği için otitis media açısından değerlendirilemedi. Kulak kepçesi ölçümü ancak 1574 ögrencide yapılabildi.

Öğrencilerin $945(\% 48,8)$ 'i kız, 993 (\%51,2)'si erkek, yaș ortalaması 8,6 2,3'tü. Kı̈ öğrencilerin yaş ortalaması 8,5 2.3 , erkek öğrencilerin 8,7 $\pm 2,4$ idi. Aralarında anlamlı fark yoktu $(\mathrm{t}=-1,405)$. Çalışmaya katılan öğrencilerin $1369(\% 70,6)$ 'u ilkokul, $569(\% 29,4)$ 'ü ortaokulda eğitim görmekteydi. Çalışmaya katılan öğrencilerin özgeçmiş ve soygeçmiş özelliklerinin dağılımları Tablo 1'de verilmiştir.

Çalışmada tonsiller hipertrofi sıklığ $\% 25,2$, kepçe kulak $\% 14,8$, otitis media \%3,3, anterior nazal deviasyon $\% 10,4$ sıklıktaydı. Çalışmaya katılan öğrencilerin yapılan kulak, burun ve boğaz muayene bulgularının ilk ve ortaokula göre dağılımı Tablo 2'de gösterilmektedir.

Erkek öğrencilerde kepçe kulak sıklığı $(\% 10,6)$ kızlardan $(\% 4,2)$ anlamlı daha yüksekti $\left(X^{2}=46,133 ; p=0,001\right)$. Diğer kulak, burun ve boğaz bozuklukları açısından anlamlı farklılık yoktu $(\mathrm{p}>0,05)$.

Alerji öyküsü olan öğrencilerde yine değerlendirilen kulak, burun ve boğaz patolojileri açısından anlamlı farklılık yoktu $(\mathrm{p}>0,05)$.

Öğrencilerden $18(\% 1,0)$ 'i yapılan muayene sonrası KBB Hastalıkları uzmanına yönlendirilirken, $230 \quad(\% 20,7)$ 'ine muayene eden hekim tarafından çeşitli tıbbi önerilerde bulunuldu (1 öğrenciye tonsillit, 1 öğrenciye sinüzit, 228 öğrenciye buşon tedavisi).

En az bir kulak, burun ve boğaz patolojisi bulunma durumunun(buşon, otitis media, anterior septal deviasyon, tonsil hipertrofisi), ögrencilerin cinsiyetlerine ve ilk ya da ortaokul seviyesinde olmalarına göre aralarında anlamlı farklılık yoktu $(\mathrm{p}>0,05)$. Anterior septal deviasyon ilkokul dönemindeki çocuklarda anlamlı olarak daha sık saptandı $(p<0,05)$. Tonsil hipertrofisi veya otitis media varlığı ile öğrencilerde alerji öyküsü, anne-babalarda sigara kullanma ve işitme kaybı öyküsü açısından anlamlı farklılık yoktu $(\mathrm{p}>0,05)$.

\section{TARTIŞMA}

Çanakkale ili okul çağı çocuklarında KBB muayenesi sonucunda en sık sırasıyla tonsil hipertrofisi, kepçe kulak deformitesi, anterior septum deviasyonu ve otitis media patolojilerinin görüldüğü saptand1. Erkeklerde daha fazla kepçe kulak deformitesi varken, anterior nazal septum deviasyonu ilkokuldaki öğrencilerde daha fazlaydı. Öğrencilerin alerji öyküsü, işitme kaybı ile ebeveynlerinin sigara ve işitme kaybı öyküleri tonsil hipetrofisi, anterior septum deviasyonu, otitis media üzerine etkili değildi.

Çocukluk döneminde en sık sağlık kuruluşlarına ayaktan hasta başvuru sebebini kulak, burun ve boğaz hastalıkları oluşturmaktadır. Çocukluk çağında başlayan ve süreğen kulak, burun ve boğaz hastalıkları büyüme gelişme geriliği, obstruktif uyku apnesi gibi ek morbiditelere yol açmaktadır.

Uzun süreli burun tıkanıklığı, burundan nefes almada güçlük ve ağızdan solunum şikayeti ile üçüncü basamak KBB polikliniğine başvuran toplam 97 çocuk hastadan 29'unda $(\% 31,9)$ tonsil boyutu evre 3,8 'inde $(\% 8,8)$ evre 4 olarak saptandı (5). Toplum tabanlı çalışmamızda çocukların 488 $(\% 25,2)$ 'inin tonsil hipertrofisinden etkilendiği saptand. Tonsil hipertrofisi evre 3 olan $69(\% 3,6)$ ve evre 4 olan $4(\% 0,2)$ öğrenci vardı. Çalışmamızda da görüldüğü gibi hastalıkların, toplumu temsil eden örneklemde gerçek sıklıklarında gözlenirken dal polikliniklerine başvuru yapanların o hastalıkla ilgili prevalansının daha yüksek olduğu dikkat çekmektedir. Bununla birlikte dal polikliniklerine daha yüksek evredeki, daha semptomatik hastalar başvurmaktadır.

Kepçe kulak deformitesi otozomal dominant kalıtım gösterirken, toplumun $\% 5$ kadarını etkilemektedir $(6,7)$. Çalışmamızda erkekleri kızlardan daha çok etkileyen kepçe 
Tablo 2. Öğrencilerin kulak, burun ve boğaz muayene bulgularının dağılımları, $n$ (\%)

\begin{tabular}{|c|c|c|c|c|c|c|}
\hline & \multicolumn{2}{|c|}{ İlkokul } & \multicolumn{2}{|c|}{ Ortaokul } & \multirow{2}{*}{$\mathbf{p}^{*}$} \\
\hline & & Muayene & Tespit & Muayene & Tespit & \\
\hline \multirow{3}{*}{ Kepçe Kulak Deformitesi } & Toplam & 1172 & $175(11,1)$ & 402 & $58(14,4)$ & 0,806 \\
\hline & $\mathrm{K} 1 \mathrm{z}$ & 593 & 52 & 176 & 14 & \\
\hline & Erkek & 579 & 123 & 226 & 44 & \\
\hline \multirow{8}{*}{ Buşon } & Toplam & 1368 & $294(21,5)$ & 569 & $105(18,5)$ & 0,407 \\
\hline & $\mathrm{K} 1 \mathrm{z}$ & 688 & 156 & 257 & 54 & \\
\hline & Erkek & 680 & 138 & 312 & 51 & \\
\hline & Grade 0 & & 1074 & & 464 & \\
\hline & Grade 1 & & 60 & & 24 & \\
\hline & Grade 2 & & 69 & & 18 & \\
\hline & Grade 3 & & 65 & & 25 & \\
\hline & Grade 4 & & 100 & & 38 & \\
\hline \multirow{3}{*}{ Otitis Media } & Toplam & 1269 & $41(2,3)$ & 529 & $21(1,2)$ & 0,922 \\
\hline & $\mathrm{K} 1 \mathrm{z}$ & 632 & 24 & 237 & 9 & \\
\hline & Erkek & 637 & 17 & 292 & 12 & \\
\hline \multirow{3}{*}{ Anterior nazal septum deviasyonu } & Toplam & 1368 & $121(6,2)$ & 569 & $80(4,1)$ & 0,001 \\
\hline & $\mathrm{K} 1 \mathrm{z}$ & 688 & 67 & 257 & 30 & \\
\hline & Erkek & 680 & 54 & 312 & 50 & \\
\hline \multirow{8}{*}{ Tonsil hipertrofisi } & Toplam & 1369 & $343(17,7)$ & 569 & $145(7,5)$ & 0,387 \\
\hline & Kiz & 688 & 178 & 257 & 69 & \\
\hline & Erkek & 681 & 165 & 312 & 76 & \\
\hline & Yok & & $1026(52,9)$ & & $424(21,9)$ & \\
\hline & Evre 1 & & $145(7,5)$ & & $73(3,8)$ & \\
\hline & Evre 2 & & $144(7,4)$ & & $53(2,7)$ & \\
\hline & Evre 3 & & $50(2,6)$ & & $19(1,0)$ & \\
\hline & Evre 4 & & $4(0,2)$ & & 0 & \\
\hline
\end{tabular}

*ki-kare testi, n:Muayenesi gerçekleştirilen öğrencilerin ailesi tarafindan anket formunda ilgili soruya verdikleri yanıt sayısı

kulak deformitesi \%14,8 sıklıktaydı. Herhangi bir sağlık sorunu oluşturmamasına rağmen kepçe kulak deformitesi, kozmetik açıdan problemlere yol açmakta ve özellikle ergenlik dönemi ve sonrasinda bu sorun nedeniyle bireyler hekime başvurmaktadır.

Burun pasajının anormal olarak sağa veya sola yönelip kısmi ya da tamamen tıkanmasina neden olan septum deviasyonu burun tıkanıklığına neden olan en sık görülen yapısal anomalidir (8). Tomografi çekimleri sonucunda görülme sıklığı $\% 40$ oranındadır (9). Ülkemizde retrospektif olarak bir yıl içinde KBB polikliniklerine başvuranların incelendiği araştırmada nazal septum derivasyonu saptanan 7958 hasta vardı. Bu çalışmada 20 ve 30'lu yaşlarda erkeklerde nazal septum deviasyonu daha sık gözlenmiştir (10). Yıldırım ve ark. nazal deviasyonun sıklığını ilkokul çağı çocuklarında \%38-39 oranında bulurken, bizim çalışmamızda \%10,3 oranında saptandı (11). Çalışmamızda ilkokul çocuklarında $(\% 6,2)$ ortaokula $(\% 4,1)$ göre daha fazla oranda gözlenirken, aralarında anlamlı farklılık yoktu.

Otitis media 3 yaşına kadar yaklaşık çocukların 2/3'ünde görülür. İlk 5 yaşa kadar sıklığı pik yaparken 6 yaş ve sonrasında sıklık azalır (12). Bazı yapısal bozukluklar (adenoid vejetasyon, tonsil hipertrofisi gibi) ile altta yatan alerji gibi ek hastalıklar otitis media sıklığını arttırmaktadır (12). Çalışmamızda otitis media saptanan toplam $62(\% 3,3)$ öğrenci vard1. İşitme kaybı olduğunu beyan eden toplam $25(\% 1,2)$ öğrenci vardı. Ülkemizde Kahramanmaraş'ta Okur ve arkadaşlarının yaptığı çalışmada 6-16 yaş arası 2930 öğrenci efüzyonlu otitis media açısından incelenmiş ve \%6,5 sıklıkta saptanmıştır (13). Kırıs ve arkadaşlarının Doğu Anadolu'da yaptığı çalışmada otitis media sıklığı \%10,43 olarak bulunmuş; otitis media ile pasif sigara maruziyeti ve allerji hikayesi arasında anlamlı ilişki saptanmışken bizim çalışmamızda istatistiksel anlam saptanmamıştır (14). 2007 yılından itibaren aşı takvimine giren Hemophilus İnfluenza aşısı ve 2008 yılında eklenen Konjuge Pnömokok aşısı ile üst solunum yollarında enfeksiyona bağlı görülen patolojilerde azalma olması beklenen bir durumdur. Bizim çalışmamızda otitis media sıklığının önceki çalışmalardan düşük olması aşılama programının başarılı olduğunu göstermektedir. Erkek cinsiyet, alerji öyküsü, sigara içimi, ailevi yatkınlık, travma gibi akut otitis media sıklığını arttıran faktörler literatürde tanımlanmışsa da çalışmamızda cinsiyet, alerji varlığı ve aile bireylerinden birinin sigara içiminin otitis media sıklığını etkilemediği gözlenmiştir (15-17).

\section{Kisıtlılıklar}

Okul tabanlı yapılan çalışmada zaman ve mekân kısıtlılığına sorunlar yaşanmıştır. Küçük yaştaki öğrenciler muayeneye uyum sağlayamadığından tüm okul katılımı gerçekleştirilmemiş ya da muayeneler eksik kalmıştır. Kullanılan anket formlarında öğrencilerin geçirdiği 
operasyonlar sorgulanmamıştır. Bu nedenle tonsillektomi olan öğrenciler saptanmamıştır.

\section{SONUÇ}

Okul çağında çocuklarda sırasıyla tonsil hipertrofisi, nazal deviasyon ve otitis media en sık gözlenmektedir. Anterior nazal deviasyon sıklığı ilkokul öğrencilerinde daha sıkken, kepçe kulak erkeklerde daha fazlaydı. Öğrencilerin alerji öyküsü, işitme kaybı ile ebeveynlerinin sigara ve işitme kaybı öyküleri tonsil hipetrofisi, anterior septum deviasyonu, otitis media üzerine etkili değildi.

\section{Çıkar çatışması: Bildirilmedi.}

Finansal destek: Bildirilmedi.

\section{KAYNAKLAR}

1. Brodsky L. Modern assessment of tonsils and adenoids. Pediatr Clinic N Am 1989; (36): 1551-69.

2. Akyıldız N:A. Otitis Media ve Tiplerinin Tanımlanması. Akyıldız N.(Eds): Kulak Hastalıkları ve Mikrocerrahisi. Bilimsel Tip Yayınevi. Ankara,1998.s 247-542.

3. Adamson JE, Horton CE, Crawford HH. Growth patterns of the external ear. Plast Reconstr Surg 1965; 36: 466.

4. Öz F, Kaytaz A, Aksoy E. Otitis Media. Toplumdan Edinilmiş Enfeksiyonlara Pratik Yaklaşımlar. Sempozyum Dizisi. İ.Ü. Cerrahpaşa Tıp Fakültesi Sürekli Tıp Eğitimi Etkinlikleri Şubat 2008; no:61 s.71-84

5. Salman N, Vezir E, Toyran $M$ at all. Çocuklarda Uzun Süreli Burun Tıkanıklığında Alerjik Rinit ve Adenoid Vejetasyon İlişkisi. Nobel Med 2015; 11(3): 17-21

6. Adamson PA, Strecker HD. Otoplasty techniques. Facial Plast Surg 1995; 11(4): 284-300.

7. Maricevich P, Contijo NF, Duprat R, Freitas F, Pitanguy I. Island Technique for Prominent Ears: An Update of the Ivo Pitanguy Clinic Experience. Aesthetic Surgery Journal. 2011;(31): 623-34.

8. Dinis PB, Haider H. Septoplasty: long-term evaluation of results. Am J Otolaryngol 2002;(23):85-90.

9. Uygur K, Tüz M, Doğru H. The correlation between septal deviation and concha bullosa. Otolaryngol Head Neck Surg 2003;(129):33-6.

10. Özkırış M, Mutlu C. Kulak Burun Boğaz polikliniğine başvuran hastalarda Nazal Septum Deviasyonu sıklığı. J Kartal TR 2010;(21):72-6.

11. Yildırım I, Okur E. Prevelance of nasal septum deviation in children from Kahramanmaras, Turkey. Int J Pediatr Otorhinolarygol 2003, (67):1203-06.

12. Subcommittee on otitis media with effusion. Committee on quality improvement. Clinical practice guideline: The diagnosis, treatment and evaluation of the otitis media with effusion. In: Clinical practice guideline of American Academy of Pediatrics, 3rd Edition, 2000, p; 337-61.

13. Okur E, Yıldırım İ, Kılıç MA, Güzelsoy S. Prevalance of otitis media with effusion among primary school children in Kahramanmaras, in Turkey. Int $\mathrm{J}$ Pediatr Otorhinolarygol 2004 (68): 557-62

14. Kırıs M, Müderris T, Kara T, Bercin S, Cankaya H, Sevil E. Prevalence and risk factors of otitis media with effusion in school children in Eastern Anatolia. Int $\mathrm{J}$ Pediatr Otorhinolarygol 2012 (76): 1030-5

15. Cober MP, Johnson CE. Otitis media: review of the 2004 treatment guidelines, Ann Pharmacother 2005 (39): 187987.

16. Neff MJ, American Academy of Pediatrics; American Academy of Family Physicians. AAP, AAFP release guideline on diagnosis and management of acute otitis media, Am Fam Physician 2004 (69): 2713-15.

17. Rosenfeld RM, Culpepper L, Yawn B, Mahoney MC, AAP, AAFP, AAO-HNS Subcommittee on Otitis Media with Effusion. Otitis media with effusion clinical practice guideline, Am Fam Physician 2004 (69): 2776-9. 